\title{
Design and Development of Stone Collector
}

\author{
M.R. Rudani*, R.G. Jakasania and R.A. Gupta \\ Department of Farm Machinery and Power Engineering, Junagadh Agricultural University, \\ Junagadh-362001, India \\ *Corresponding author
}

\begin{abstract}
A B S T R A C T
Keywords

Stones, Design,

Digging tool,

Stones picker

Article Info

Accepted:

12 March 2018

Available Online:

10 April 2018

In a many Farm fields, stones are present in the soil. Stones are a major problem in a farm to resist the growth of plants. It is also damage the tillage tools and harvesting machinery. The damage of harvesting machinery can be very expensive and takes substantial periods of time to repair. Most of Indian farmers collect stones manually. In a process of removing stone, operation involves digging up the stones and separating it from the soil. But manual collection of stones fail to dig out all the stones from the field and many stones still remain in the ground after collecting stones from the field. Hence, it was planned to fabricate a stone collecting machine and to study its performance. Major components of the developed machine are digging blade, conveying unit, stone collecting trolley and power transmission system. A frame holds the different components of machine. Digging blade was hold with help of four nut-bolts which are mounted on frame. PTO operated conveyor was attached at the upper edge of digging blade which is operated at the speed of $33.6-42.0 \mathrm{~m} / \mathrm{min}$.
\end{abstract}

\section{Introduction}

India can be called a land of paradoxes because of the large variety of soils. A girdle of high mountains, snow fields, glaciers and thick forests in the north, seas washing lengthy coasts in the Peninsula, a variety of geological formations, diversified climate, topography and relief have given rise to varied physiographic features (Bhattacharyya et al., 2013).

Farm fields in many areas have stones mixed with the soil. Stones are found in all shapes and sizes. In dry region the soil contains a number of small stones due to which farmers face difficulties during cultivation (Smith,
2000). Hence it becomes essential to remove these stones from the field, improves the structure and texture of the soil, increase the water holding capacity of the soil, and make the soil easy for nursery preparation and other operation. These problems prevent the fiscal growth of farmer and ultimately hamper the development of their farmland and family. Efficient, effective, cheap and productive techniques are needed to strengthen the farmers (Syed et al., 2016).

The process of removing stone involves digging up the stones and separating it from the soil. But manual collection of stones fail to dig out all the stones from the field and many stones still remain in the ground after 
collecting stones from the field. The working capacity of a human labor varies in the course of a day. Generally, it is higher in the morning and declines in the middle of the day. Again in the afternoon it increases for a short period and then falls rapidly (Keigley, 2006).

Stone collecting as of today in the country is labour intensive and tedious. The manual picking is mostly performed in sitting or bending posture, which rapidly increases fatigue. Stone pickers are used in landscapes where stones need to be removed from the soil and ground surface to prevent damage to other farm machinery.

Huge amount of labour is engaged and its availability is the major problem faced by the farmers. In general, women's engaged in the removal of stones in dry farmlands undergo serious physical stress while doing such field operation. Removing stones from the soil also ensures a more consistent yield. Thus, there is a need for a smaller and efficient machine to pick up the stones with ease and also which would be more accessible and also considerably cheaper.

\section{Materials and Methods}

A stone collecting machine was developed to collect the stones from agricultural fields. The stone collecting machine consists of a frame with digging blade, conveying system, collection trolley and power transmission system to provide power to conveying system and three-point linkage unit. The working principle of stone collecting machine which is having a blade will dig out stones and these stones along with the soil will be separated by a conveyor provided in the machine. When a mixture of stones and soil is lifted on by conveyor, stones will get separated and soil will pass through the conveyor. Due to motion of conveyor belt, the stones will move towards collecting trolley.

\section{Design considerations}

The components of stone collector were designed and fabricated based on the parameters like functional requirements, engineering and general considerations. The assumptions made in the design of stone collector are as follow:

Speed of Power Take Off shaft was taken as $540 \pm 10 \mathrm{~min}^{-1}$.

Average speed of operation of tractor in the field was kept as $2 \mathrm{~km} \cdot \mathrm{h}^{-1}$.

Maximum soil resistance was considered as $0.75 \mathrm{~kg} \cdot \mathrm{cm}^{-2}$.

Coefficient of friction in un-ploughed soil was taken 0.85 .

The machine should dig stones from the field in $115 \mathrm{~cm}$ width and $10 \mathrm{~cm}$ depth.

\section{Assessment of draft and power requirement}

The draft requirement of the tractor operated stone collector would be estimated using factors related to implement and the type of soil.

Cross section area of blade $=$ length of blade $\times$ depth of cut $=115 \times 10=1150 \mathrm{~cm}^{2}$

Maximum draft $=$ cross section area of blade $\times$ soil resistance $=1150 \times 0.75=862.5 \mathrm{~kg}$

Speed of travel $=2.5 \mathrm{~km} / \mathrm{h}=2500 \mathrm{~m} / \mathrm{h}=0.69$ $\mathrm{m} / \mathrm{s}$

The power required for the designed draft was estimated using following formula (Kepner $e t$ al., 2005).

$P=\frac{D \times S}{1000}$ 
Where:

$\mathrm{P}=$ Power required $(\mathrm{kW})$,

$\mathrm{D}=$ Maximum $\operatorname{draft}(\mathrm{N})$,

$\mathrm{S}=$ Forward speed. $(\mathrm{m} / \mathrm{s})$.

$P=\frac{862.5 \times 9.81 \times 0.69}{1000}=5.83 \mathrm{~kW}=7.82 \mathrm{HP}$

Horse power required to operate the implement in soil $=\frac{\text { Total power required }}{\text { Coefficient of friction }}$

Horse power required to operate the implement in soil $=\frac{7.82}{0.85}=9.2 \mathrm{HP}$

Hence, this implement can easily be hitched and operated by most of the Indian makes tractors of 35 HP capacity.

\section{Design of functional components of stone collector}

The design of the functional components and different mechanisms were carried out. The machine consists of frame, blade, separating unit and power transmission system.

The design of following components was taken up:

Conveying unit

Bevel gear mechanism

Belt pulley mechanism

\section{Design of conveying unit}

The conveyor was provided on the upper edge of the blade. The soil-stone separating unit consists of conveyor $(988 \mathrm{~mm}$ x $860 \mathrm{~mm})$. The conveyor was made of M.S. bars and angles.

For the determination of volume of material flow on the conveyor, the volume of the material flow on the conveyor was determined as follows (Khurmi and Gupta, 2011):
Volume of soil mass = Area of coverage of the blade $\times$ forward speed of travel $=$ $\frac{1.1 \times 0.10 \times 2500}{3600}=0.076 \mathrm{~m}^{3} / \mathrm{s}$

Weight of soil to be handled $=$ Volume of soil mass $\times$ Bulk density of soil $\left(\mathrm{kg} / \mathrm{m}^{3}\right)=0.076$ $\times 1230=93.48 \mathrm{~kg} / \mathrm{s}$

Weight of stones to be handled $=$ Volume of soil mass $\times$ Bulk density of stones $\left(\mathrm{kg} / \mathrm{m}^{3}\right)=$ $0.076 \times 865=65.74 \mathrm{~kg} / \mathrm{s}$

Total material to be handled $\mathrm{Q}_{\text {out }}=$ Weight of soil + Weight of stones $=93.48+65.74=$ $159.22 \mathrm{~kg} / \mathrm{s}$

Now equating the volume of material flow with volume of the conveyor by assuming that this material will be spread uniformly on the conveyor, the following was obtained:

Qout $=$ Bulk density of soil $\times$ length of blade $\times$ thickness of material $(\mathrm{m}) \times$ speed of conveyor $159.22=1230 \times \mathrm{L} \times 0.1 \times 1.5$

$\mathrm{L}=0.86 \mathrm{~m}=86 \mathrm{~cm}$

Therefore, the conveyor of $86 \mathrm{~cm}$ length was fabricated using M.S. rod of $10 \mathrm{~mm}$ diameter. The conveyor was supported by flat metal wheel having $70 \mathrm{~mm}$ diameter at front, centre and rear side. All the wheels are supported by the shaft of $40 \mathrm{~mm}$ diameter and the shaft was fitted in pulley.

The top end of conveyor is rigidly fixed with main frame. To tighten the conveyor elevator a nut and bolts was provided, which moved in a slot, to stretch the elevator by moving the driving shaft away.

At the middle of the separating unit two flat metal wheel were provided with belt at front and rear side. The design of the separating unit was based on its functional requirements. 


\section{Bevel gear mechanism}

The power was transmitted to shaft through bevel gear mechanism.

The size selection of bevel gear was carried out using standard formula (Khurmi and Gupta, 2011).

$\frac{N_{1}}{N_{2}}=\frac{T_{2}}{T_{1}}$

Where,

$\mathrm{N}_{1}=$ No. of revolution of driving wheel (540)

$\mathrm{N}_{2}=$ No. of revolution of driven wheel

$\mathrm{T}_{1}=$ No. of teeth on driving gear (10)

$\mathrm{T}_{2}=$ No. of teeth on driven gear (18)

Substituting the values as above the number of revolution of driven wheel comes out as.

$N_{2}=\frac{540 \times 10}{18}=300 \mathrm{rpm}$

To get required number of rpm standard bevel gears of 10 and 18 teeth were used.

\section{Belt pulley mechanism}

The power was transmitted to shafts of conveyor through belt and pulley mechanism. The selection of size was carried out using standard formula (Khurmi and Gupta, 2011).

$\frac{N_{1}}{N_{2}}=\frac{D_{2}}{D_{1}}$

$N_{2}=\frac{300 \times 10}{15}=200 \mathrm{rpm}$

Standard pulleys of 10 and 15 diameter were used.

\section{Fabrication of stone collector}

\section{Frame}

The frame is meant for holding different components of stone collecting machine. It is subjected to bending, tension, and vibrations. The frame was fabricated using L-section angle iron for mounting digging blade, separating unit and power transmission unit. The components were fastened on the main frame using nuts and bolts. The frame was provided with three hitch points to mount the machine on tractor. The three point hitch was fabricated using $75 \mathrm{~mm} \times 5 \mathrm{~mm}$ flat. The rear end of the frame was supported on two wheels for proper stability and easy transportation of the machine (Fig. 1).

\section{Digging blade}

The function of the blade of machine is to lift or dig up the layer of soil stones, partially or completely break up the soil layer and deliver the resulting material to the subsequent working components. The length of the blade was decided $1.15 \mathrm{~m}$ on the basis of dimension of tread width of the tractor of 35-45 hp range. The width of blade was decided $25 \mathrm{~cm}$ such that to cover $10 \mathrm{~cm}$ depth of cut for digging. The blade was fabricated using $7 \mathrm{~mm}$ thickness spring steel. The blade was supported with nuts and bolts at the both side such that it inclined at 23 degree with the horizontal plane (Fig. 2).

\section{Stone collecting trolley}

The stone collecting trolley is used for collection of stones. It is provided at the rear side of the conveyor. The stone collecting trolley is made of $10 \mathrm{~mm}$ iron bars. The size of trolley is $118 \mathrm{~cm} \times 45 \mathrm{~cm} \times 25 \mathrm{~cm}$. The collected stones conveyed by conveyor and dropped into the collecting trolley which is supported by two rubber wheels and one gate 
is provided in the rear side of trolley for the unloading of the filled stones (Fig. 3).

\section{Power transmission system}

The conveyor was driven by P.T.O. of the tractor. The rotating motion of the P.T.O shaft was transmitted to the driving gear through shaft, gear reduction unit and belt pulley. Power transmitted from PTO to bevel gear which is having 1:1.8 bevel gear ratio.

So that shaft-I transmits $540 \mathrm{rpm}$ to shaft-II at $300 \mathrm{rpm}$. Shaft-II was connected to belt and pulley transmission system which transmits $200 \mathrm{rpm}$. Shaft was clamped on two bearings and care was taken on its alignment with the gear reduction input shaft.

\section{Experimental procedure}

The instruments and equipment used for the field test were two tractors, measuring tape, soil sample auger, metallic core cylinder, digital dynamometer, stop watch, etc. Before conducting the actual field test, necessary settings and proper attachments were made and preliminary tests were conducted. Tractor drive wheel was marked with colored tapes for easy counting of number of revolutions during slip measurement. The performance parameters like bulk density, moisture content of the soil, depth and width of cut, fuel consumption, draft, field capacity and slip were determined. The other details of experimental fields are given in Table 1.

\section{Results and Discussion}

While designing and development of the tractor operated stone collector, the basic emphasis was given on simplicity of fabrication, use of locally available material and minimum cost of fabrication. Anticipated view of developed stone collector shown in Figure 4(b) and its specifications with all units is shown in Table 2. Results obtained during the field performance of the developed stone collector are shown below performance parameters like draft, wheel slip, fuel consumption and field efficiency are discussed.

Fig.1 Detailed drawing of frame

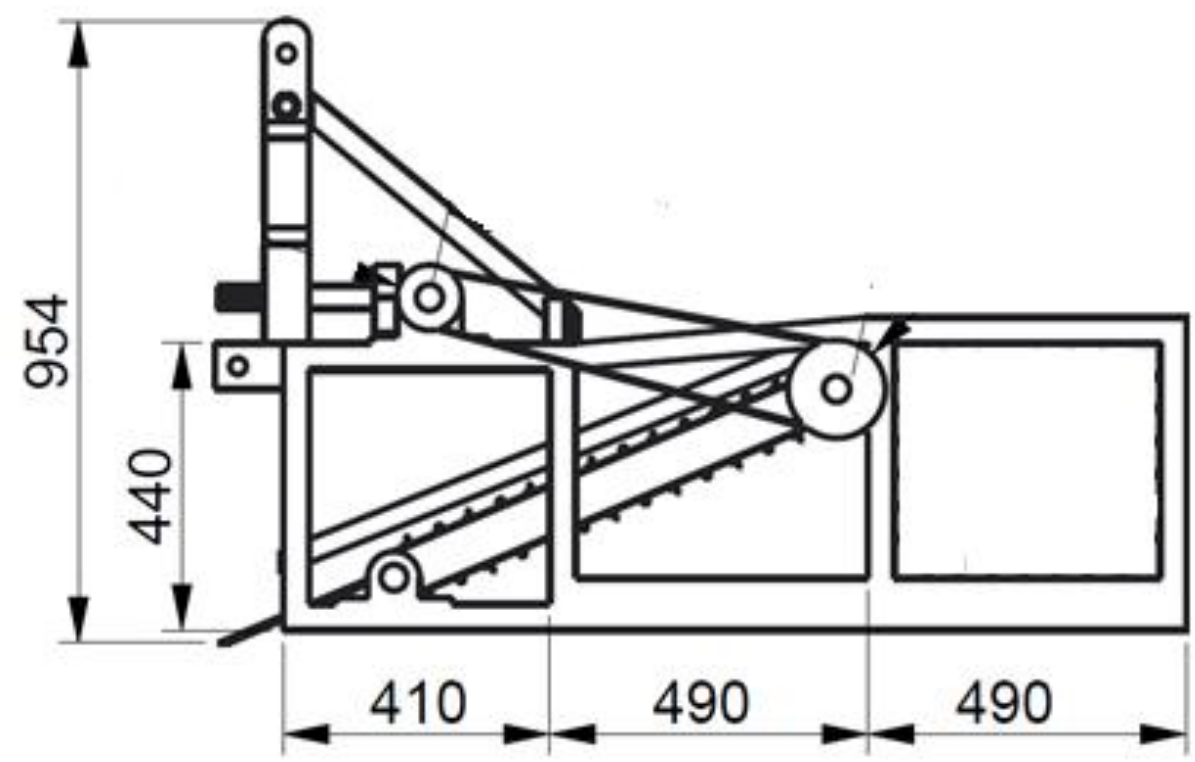


Fig.2 Detailed drawing of digging blade

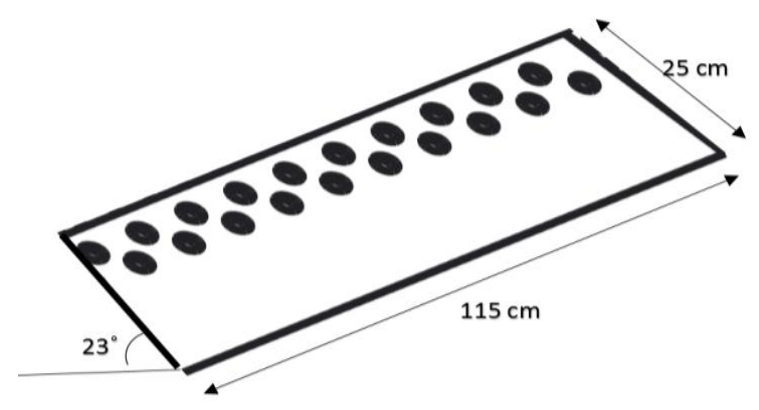

Fig.3 Stone collecting trolley

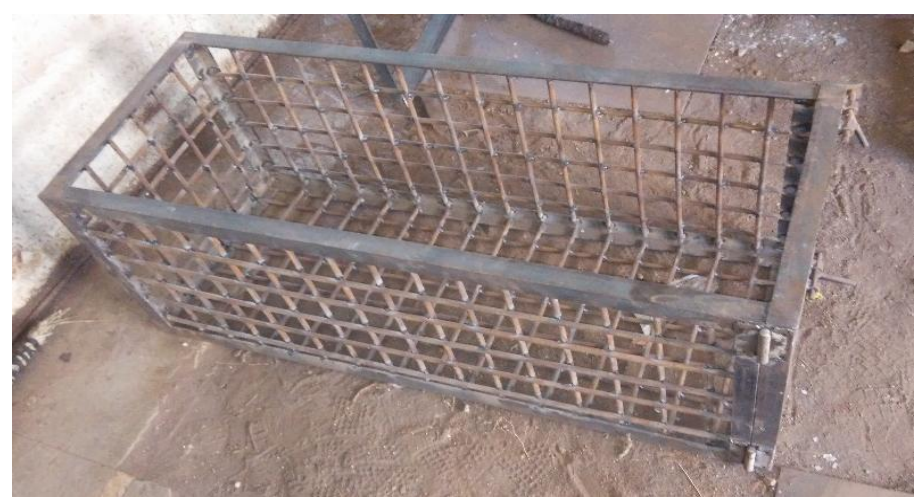

Fig.4 a. Detailed drawing of stone collector; b. Developed stone collector
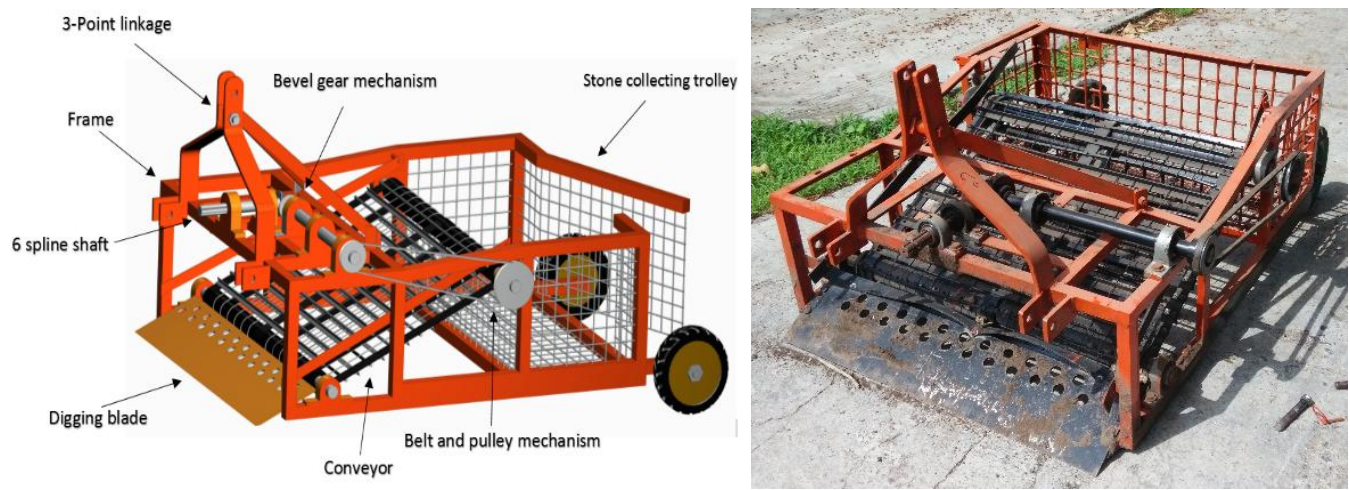

Table.1 Details of experimental field

\begin{tabular}{|c|c|}
\hline Parameters & Field \\
\hline Type of soil & Medium black \\
\hline Moisture content, \% (d.b.) & 10.85 \\
\hline Total area of experimental field, $\mathrm{m}^{2}$ & 1242 \\
\hline Shape of field/plot & Rectangular shape \\
\hline Bulk density, g/cc & 1.23 \\
\hline
\end{tabular}


Table.2 Detailed specifications of stone collector

\begin{tabular}{|l|l|l|}
\hline Sr. & Particular & Specifications \\
\hline $\mathbf{2}$ & $\begin{array}{l}\text { Name of the equipment } \\
\text { Type of hitch and its detail }\end{array}$ & Stone collector \\
\hline & $\begin{array}{l}\text { Linkage } \\
\text { Powered by }\end{array}$ & 3 - point \\
\hline 3 & Overall Dimensions & \\
\hline $\begin{array}{l}\text { Length } \\
\text { Width }\end{array}$ & $1240 \mathrm{~mm}$ \\
\hline Height & $1810 \mathrm{~mm}$ \\
\hline Weight & $950 \mathrm{~mm}$ \\
\hline Main Frame & $190 \mathrm{~kg}$ \\
\hline Material of construction & Mild Steel $(\mathrm{L}-$ section size: $40 \mathrm{~mm} \times 40 \mathrm{~mm} \times 3 \mathrm{~mm})$ \\
\hline Length & $1170 \mathrm{~mm}$ \\
\hline Width & $1500 \mathrm{~mm}$ \\
\hline Digging blade & Spring steel blade \\
\hline Material of construction & Flat type with holes \\
\hline Shape & $1150 \mathrm{~mm}$ \\
\hline Length & $250 \mathrm{~mm}$ \\
\hline Width & $7 \mathrm{~mm}$ \\
\hline Thickness & Two tynes by bolting \\
\hline Fixed with & $23^{\circ}$ \\
\hline Inclination angle & \\
\hline Conveyor & $98 \mathrm{~cm}$ \\
\hline Length & $86 \mathrm{~cm}$ \\
\hline Width & $23^{\circ}$ \\
\hline Angle & $50 \mathrm{~mm}$ \\
\hline Belt strip width & $10 \mathrm{~mm}$ \\
\hline Diameter of rod & $50 \mathrm{~mm}$ \\
\hline Spacing between rods & 14 \\
\hline Number of L- section & 14 \\
\hline Number of iron bars & $70 \mathrm{~mm}$ \\
\hline Diameter of metal roller & Stone collecting trolley & $1180 \mathrm{~mm}$ \\
\hline Length & $450 \mathrm{~mm}$ \\
\hline Width & $250 \mathrm{~mm}$ \\
\hline Height & & \\
\hline
\end{tabular}

Overall dimensions of developed stone collector are $1240 \mathrm{~mm}$ length, $1810 \mathrm{~mm}$ width and $950 \mathrm{~mm}$ height. Developed stone collector was test in field and following performance parameters were obtained.
Average depth of cut $10 \mathrm{~cm}$ for stone collector was observed. Stone collector worked at higher working depth of operation. The effect of wheel slip during operation of developed stone collector was recorded 
7.58\%. Draft was also determined and the value of draft $2107 \mathrm{~N}$ for stone collector was recorded. Field efficiency was determined by standard procedure during operation and the mean value of field efficiency was $76.05 \%$. Fuel consumption was determined by standard procedure and quantity of fuel during the operation of stone collector was recorded $4.01 \mathrm{l} / \mathrm{h}$.

The developed stone collector has worked satisfactorily in the field. The average field efficiency, fuel consumption and cost of operation was $76.05 \%, 4.01 \mathrm{l} /$ hand 2717.33 Rs/ha respectively. The developed stone collector was found effective in the Saurastra region of Gujarat. A medium size of tractor can meet the draft. The field efficiency was found satisfactory and fuel consumption was significantly reduced compared to other implement. The stone collecting machine enables the task to be completed in the shortest time with minimum operating cost and energy requirement. It would replace the traditional practice of manual stone collecting and may lead to save time and cost.

\section{References}

Bhattacharyya, T., Pal, D., Mandal, C., Chandran, P., Ray, S., Sarkar, D., Srivastava, A., Sidhu, G. and Singh, R. 2013. Soils of India: historical perspective, classification and recent advances. Journal of Current Science. 104(10): 1308-1323.

Keigley, K. V. 2006. Rock separator with beveled tines and removable grates. United States Patent. No.7066275 B1 (27 July, 2006).

Kepner, R. A., Bainer R., Barger E.L. 2005. Principles of Farm Machinery. CBS Publishing Company. New Delhi, India.

Khurmi, R. S. and Gupta, J. K. 2011. A Textbook of Machine Design. S. Chand Publications. Ch-5, 120-180.

Smith, E. R. 2000. Rock picker. United States Patent. No. 6041866 (28 March, 2000).

Syed, M. N., Wankhade, A. M., Kalandare, S., Kharwade, R. and Hole S. 2016. Design of agriculture stone picker. International Journal for Engineering Applications and Technology. 6(2): 7174.

\section{How to cite this article:}

Rudani, M.R., R.G. Jakasania and Gupta, R.A. 2018. Design and Development of Stone Collector. Int.J.Curr.Microbiol.App.Sci. 7(04): 1424-1431.

doi: https://doi.org/10.20546/ijcmas.2018.704.161 